\title{
Arrhythmogenic right ventricular cardiomyopathy (ARVC): case report and review of literature
}

\author{
Usha Rao, ${ }^{1}$ S Agarwal, ${ }^{2}$ T J Gilbert ${ }^{1}$
}

- Additional material is available. To view please visit the journal online (http://dx. doi.org/10.1136/heartasia2014-010569).

${ }^{1}$ Department of Cardiology, University Hospital of Norfolk \& Norwich, Norwich, UK ${ }^{2}$ Department of Cardiology, Papworth Hospital, Cambridge, UK

\section{Correspondence to}

Dr T J Gilbert, Consultant Cardiology Interventionist, Clinical Director, Department of Cardiology, University Hospital of Norfolk \& Norwich, Norwich NR4 7UY, UK;

timothy.gilbert@nnuh.nhs.uk

Received 20 August 2014 Accepted 14 September 2014

CrossMark

To cite: Rao U, Agarwal S, Gilbert TJ. Heart Asia 2014;6:145-149.

doi:10.1136/heartasia-2014010569

\section{ABSTRACT}

Arrhythmogenic right ventricular dysplasia (ARVD) is an inherited condition characterised by fibrofatty replacement of the right ventricle. It causes sudden death in $30 \%$ of young adults and in $5 \%$ of those less than 65 years of age. As the presentation is non-specific, ARVD can be a diagnostic challenge leading to delayed treatment. We report a case along with the review of literature, of a 63-year-old man who presented (atypical) with a history of palpitations, dizziness and raised cardiac enzymes associated with ECG changes in the inferior and anterior leads. Further investigation helped in confirming this rare and potentially fatal cardiac condition.

In 1978 Frank and Fontain first described ARVD (arrhythmogenic right ventricular dysplasia) in six patients presenting with ventricular tachycardia (VT). ${ }^{1}$ It was defined as "total or partial replacement of right ventricular muscle with fibro-fatty tissues associated with LBBB (left bundle branch block) morphology arrhythmias". WHO and the International Society and Federation of Cardiology in 1996 further described it as part of cardiomyopathy (arrhythmogenic right ventricular cardiomyopathy, ARVC). Since then, it has been the focus of attention of experts, as it is an important cause of death in patients $<30$ years of age and forms up to $20 \%-25 \%$ of sudden deaths in young people and especially young athletes in Italy. ${ }^{23}$

\section{CASE REPORT}

A 63-year-old man presented with palpitations and presyncope. He denied chest pain or loss of consciousness. He was an ex-smoker and had stable coronary artery disease. Systemic examination was normal, as were the blood tests apart from elevated troponin levels. ECG showed T wave inversions in inferior and anterior leads. He was treated for acute coronary artery syndrome. Meanwhile, the patient had a run of non-sustained VT of left bundle branch morphology (figure 1). Transthoracic echocardiogram (TTE) revealed preserved left ventricular (LV) function but severely impaired and dilated right ventricle (RV) (see online supplementary video files). In view of TTE findings and VT, right heart aetiology, especially ARVD was suspected, although the differential diagnosis could include RV infarction with right heart failure, pulmonary pathology, etc. Increased amplitude ECG demonstrated characteristic epsilon waves in the anterior leads (figure 2). Cardiac MR was supportive of ARVD because of the epicardial fat in the margins of dilated and severely impaired RV and aneurysms (figure 3), thereby fulfilling major diagnostic criteria. Coronary angiogram revealed mild coronary artery disease. The patient was started on antiarrhythmics and referred to a specialist centre for an expert electrophysiology opinion. Detailed history revealed that two of his family members in Italy had palpitations and had intracardiac defibrillator (ICD) implanted. Patient refused ICD implantation but consented to medical treatment. He was then discharged with follow-up. Further screening was advised to his family members.

\section{AETIOLOGY}

As far as aetiology is concerned, a number of theories to explain this condition have been proposed which include dysontogenetic, degenerative, inflammatory, transdifferentiation, apoptogenic and infective. ${ }^{45}$ But the exact mechanism remains still unknown.

\section{INCIDENCE AND PREVALENCE}

True incidence of this disease is not known but the prevalence is approximately $0.02-0.1 \%$ in the general population. ${ }^{4}$ There is a wide variation seen geographically; in the USA, ARVC causes $5 \%$ of sudden cardiac deaths (SCDs) in individuals under the age of 65 years and at least 3-4\% of deaths in young athletes. On the other hand, in the Veneto region of Italy, ARVC is the most common cause of sudden arrhythmic deaths in individuals under the age of 35 years and the main cause of sudden death in young athletes in Italy. ${ }^{6}$ Men are more commonly affected. The diagnosis of ARVC is made in $80 \%$ of cases in patients below the age of 40 years. Hence, it should be suspected in young patients presenting with unprecedented history of syncope, cardiac arrest or arrhythmias.

\section{CLINICAL PRESENTATION}

Patients with ARVC may have a wide range of presenting symptoms, varying from fatigue, atypical chest pain, syncope or acute coronary syndrome. Main presenting features include:

1. Arrhythmias: Generally with left bundle branch block morphology, as they are originating from the RV.

2. SCD: ARVC is responsible for SCD for approximately $5 \%$ of patients under the age of 65 years and for $3-4 \%$ deaths in young athletes. The annual mortality rate varies from $3 \%$ in the untreated to $1 \%$ in those with pharmacological medical treatment (not including ICD treatment). ${ }^{6}$ The cause of SCD is commonly VT degenerating into ventricular fibrillation (VF). The fibrofatty deposits form the substrate required to trigger these events induced by adrenergic stimulation. 


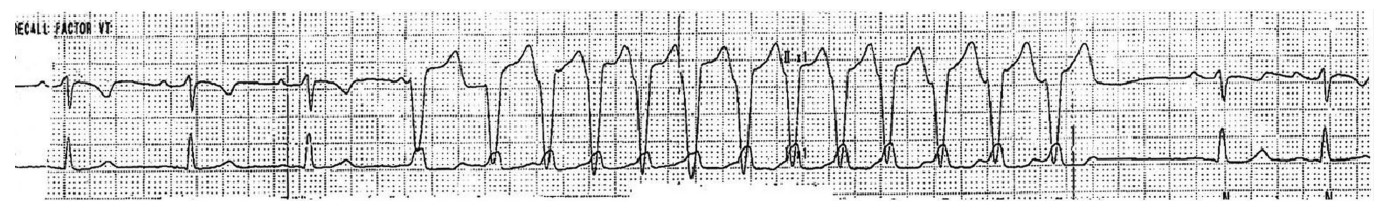

Figure 1 Rhythm strip showing a run of non-sustained ventricular tachycardia.

3. Heart Failure: Patients may develop isolated RV failure or left-sided failure. This is generally seen in the fourth or the fifth decades ${ }^{7}$ and is due to dilatation and thinning of the RV.

4. In addition, patients may present with frequent ventricular ectopics $>1000$ beats/day.

\section{NATURAL HISTORY}

The natural history of ARVC depends on the rate of progression of RV dysfunction and the symptoms/presentation. The mortality rate has been reported to be in the range of 4-20\%. It seems to be equal in men and women, though peaking in the fourth decade. It is stated to account for $5 \%$ of deaths in young adults and $25 \%$ deaths in athletes. ${ }^{4} \mathrm{Bi}$-and RV heart failure is known to occur in a period of 4-8 years after the development of complete right bundle branch block (RBBB). This has also been linked with cardiovascular mortality independently. ${ }^{4}$

In view of this, it is of great importance that this condition is identified and the treatment commenced.

\section{DIAGNOSIS}

A definitive diagnosis of ARVC requires histological demonstration of fibrofatty, this in turn requires myocardial biopsy which may be difficult because of the patchy nature of the deposits, also interventricular septum is the most common site of biopsy and in ARVC the septum may be involved quite late, a diagnostic criterion was described in 1994 in a Task Force report, ${ }^{8}$ based on major and minor criteria involving structural, genetic, ECG, arrhythmia and histological factors (some of which are described below). In 2002, it was modified for first-degree relatives. ${ }^{9}$ More recently, studies have been conducted to determine screening interval and testing for strategy at-risk relatives of patients with ARVC. ${ }^{10}$

The only criticism of the diagnostic criteria was that though very specific, it was not very sensitive for early and familial diseases. This has been further modified in the Task Force recommendations in $2010^{11}$ (box 1).

\section{ECG CHARACTERISTICS}

Approximately $90 \%$ of patients present with ECG abnormalities. The important ones include $\mathrm{T}$ wave inversions in leads $\mathrm{V} 1-\mathrm{V} 3$, which are seen in about $54 \%$ of the patients (in the absence of RBBB). ${ }^{12}$ It is important to remember that this can be a normal variant in children and in young, trained athletes and is therefore useful only in patients over the age of 12 years. In addition, complete $\mathrm{RBBB}$ is seen in $15 \%$ and incomplete in $18 \%$ of patients with $\mathrm{ARVD}^{13}$ and with the presence of QRS (complexes of $>50 \mathrm{~ms}$ ) in leads V1-V3 as compared with V6 forms a major criterion. ${ }^{14}$ Epsilon waves, which are postexcitation electrical potentials that occur at the end of QRS complex are seen in 30\% of all cases of ARVD. They are very specific of ARVD and are due to delayed RV activation. In addition, presence of prolonged QRS duration of $>110 \mathrm{~ms}$ in precordial leads and presence of RBBB with QRS precordial dispersion of $>50 \mathrm{~ms}$ is a predictor of arrhythmic events. ${ }^{6}$ Late action potentials on signal averaged ECG, especially on the left precordial leads are a minor criterion for diagnosis of ARVD. Several studies have also shown a relation between ARVC and Brugada syndrome. ${ }^{4}$

\section{ECHOCARDIOGRAPHY}

The major echocardiographic findings include RV dilation, localised aneurysms, enlarged left atria (LA), dilated RV outflow tract, increased reflectivity of moderator band, prominent trabeculations of RV apex and inferobasal dyskinesis. Other important parameters include RV end-systolic and end-diastolic diameters and ratio of RV to LV end-diastolic diameters. A ratio of $>0.5$ has a sensitivity of $86 \%$, specificity of $93 \%$ and a positive predictive value of $86 \%$ in confirming the diagnosis of ARVC. $^{13}$

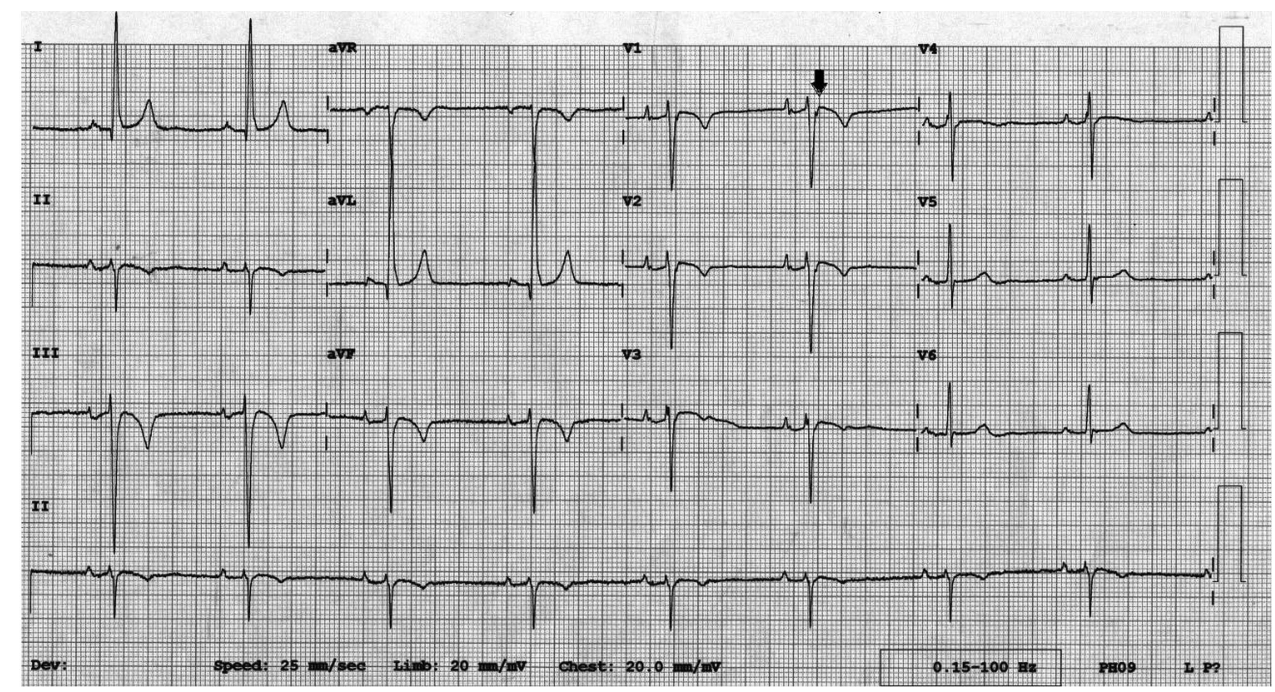

Figure 2 ECG showing epsilon waves at the terminal end of QRS complex in the anterior leads (black arrow). 


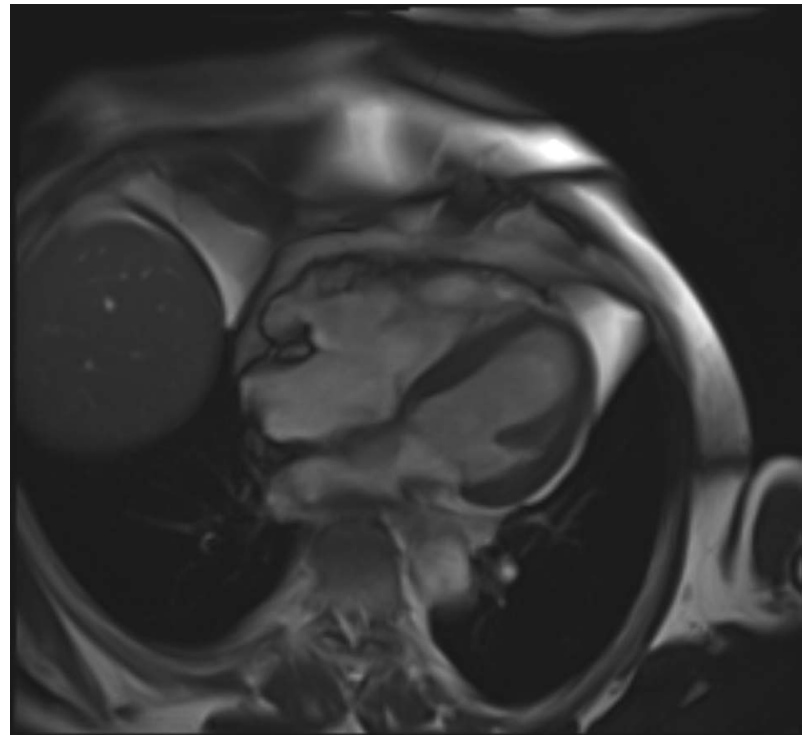

Figure 3 Cardiac MR demonstrating dilated right ventricle (RV) with the presence of epicardial fat in the RV margins and normal left ventricle.

\section{RV ANGIOGRAPHY}

RV ventricular angiography is still considered to be important for diagnosing ARVC by many but because it is invasive and associated with complications such as arrhythmias it is no longer used as a primary diagnostic tool and is largely superseded by magnetic resonance imaging (MRI). The findings include infundibular aneurysms, apical aneurysms, prominent moderator band, diastolic bulging of inferior wall, thick trabeculations, and in some tricuspid valve prolapse. ${ }^{12}$

\section{COMPUTERISED TOMOGRAPHY (CT)}

CT scan is helpful in visualising the RV and the LV because of its high resolution and is also of use in patients with ICDs. It helps to identify the presence of epicardial fat, intramyocardial fat deposits, trabeculations and dilated hypokinetic RV. However, high radiation burden limits its usefulness as an initial screening tool. $^{4}$

\section{MRI}

MRI is considered to be the one of the important and accurate non-invasive tests available to diagnose ARVC. It helps to analyse RV anatomically, morphologically and functionally. It is useful in demonstrating intramyocardial fat deposits, wall thinning, hypertrophy, trabeculations, right ventricular outflow tract (RVOT) enlargement, presence of RV aneurysms, RV dilation, failure of systolic thickening and impaired global RV function.

In addition, MRI has been used for diagnosing ARVC using anatomical, morphological and functional criteria including: presence of high intensity areas indicating fat deposits, RVOT ectasia, dyskinesia, RV dilatation and right atrial (RA) enlargement. ${ }^{15}$ However, this technique may be limited because of thin RV free wall resulting in difficulty in assessing RV thickness and in identifying intramyocardial fat in the presence of epicardial and pericardial fat deposits. ${ }^{16}$

\section{RADIOISOTOPE TECHNIQUES}

These techniques though useful in diagnosing SCD in patients by demonstrating RV and LV involvement, are not the first-line

\section{Box 1 Criteria for diagnosis of RV dysplasia}

I. Global or regional dysfunction and structural alterations MAJOR*

Severe dilation and reduction of RV ejection fraction with no (or only mild) LV impairment. Localised RV aneurysms (akinetic or dyskinetic areas with diastolic bulging).

Severe segmental dilation of the RV.

MINOR

Mild global RV dilation or ejection fraction reduction with normal LV.

Mild segmental dilation of the RV. Regional RV hypokinesia.

II. Tissue characterisation of walls MAJOR

Fibrofatty replacement of myocardium on endomyocardial biopsy.

III. Repolarisation abnormalities

MINOR

Inverted T waves in right precordial leads (V2 and V3) (people aged more than 12 years; in absence of right bundle branch block).

IV. Depolarisation/conduction abnormalities MAJOR

Epsilon waves or localised prolongation $(110 \mathrm{~ms})$ of the QRS complex in right precordial leads (V1-V3). MINOR

Late potentials (signal-averaged ECG).

\section{Arrhythmia}

MINOR

Left bundle branch block type ventricular tachycardia (sustained and non-sustained) (ECG, Holter, exercise testing).

Frequent ventricular extrasystoles (more than 1000/24 h) (Holter).

VI. Family history

MAJOR

Familial disease confirmed at necropsy or surgery. MINOR

Familial history of premature sudden death (35 years) due to suspected RV dysplasia.

Familial history (clinical diagnosis based on present criteria).

*Detected by echocardiography, angiography, MRI or radionuclide scintigraphy.

The diagnosis of ARVD/ARVC would be fulfilled by the presence of 2 major, 1 major plus 2 minor, or 4 minor criteria from different groups. ${ }^{11}$

ARVC, arrhythmogenic right ventricular cardiomyopathy; ARVD, arrhythmogenic right ventricular dysplasia; LV, left ventricle or left ventricular; RV, right ventricle or right ventricular.

diagnostic tools mainly because of their suboptimal spatial resolution and exposure to radiation. ${ }^{4}$

\section{GENETIC FACTORS}

ARVC has a strong family predilection; it is commonly inherited as autosomal dominant trait with various degrees of penetrance and polymorphic phenotypical expression. Several ARVC loci to chromosomes have been identified, this includes $14 \mathrm{q} 23$ - 
q24(ARVD1),1q42-q43(ARVD2),14q12-q22(ARVD3), $\quad 2 \mathrm{q} 32$ (ARVD4), 3p23(ARVD5), 10p12-14(ARVD6), 10q22,6p24 (ARVD8) and 12p11(ARVD9). ${ }^{17}$ An autosomal recessive variant associated with palmoplantar keratosis has been mapped to 17q21 (Naxos disease). In addition, cardiac ryanodine receptor gene (RyR2) association with ARVC has also been recently described. ${ }^{4}$

Genetic screening therefore is very useful in detection and risk stratification, in family members with little or no symptoms, but genetic testing can only support a diagnosis of ARVC not make it. Having a mutation does not necessarily mean that the patient will present clinically, only that they are at risk. This is useful when considered along with other criteria to make the diagnosis of ARVD. ${ }^{18}$

\section{HISTOLOGY}

The most characteristic histological feature of ARVC is replacement of myocytes with fibrofatty tissue and thinning of the RV wall. This begins at subepicardium and progresses to endocardium. ${ }^{7}$ Most frequently involved areas are RV inflow, the apex and the infundibulum. These three form the 'triangle of dysplasia' ${ }^{16}$ though interventricular septum and LV free wall may also be involved. Histology forms one of the major criteria for definitive diagnosis of this condition (box 1).

\section{MANAGEMENT OF PATIENTS WITH ARVC}

The main treatment modalities for ARVC include

\section{PHARMACOLOGICAL THERAPY}

Despite the importance of antiarrhythmic drugs in ARVC there are no clinical trials focusing on their efficacy in these patients. $\beta$-blockers and amiodarone are considered useful for patients with asymptomatic ARVC to suppress adrenergically stimulated arrhythmias. Studies that have been carried out on sotalol prove it to be more effective than $\beta$-blockers and amiodarone for inducible and non-inducible $\mathrm{VT}^{19}$ during programmed stimulation in $68 \%$ but its efficacy in preventing sudden death is unknown. In some cases, verapamil can also be considered. In a recent study of patients with ICDS amiodarone proved to be more effective than $\beta$-blockers and sotalol. Antiarrhythmic drugs are useful in patients with ICDs and ventricular arrhythmias. $^{20}$

\section{RADIOFREQUENCY ABLATION}

Radiofrequency ablation may be attempted in non-responders or those intolerant of medical treatment but it is not very effective and may need multiple procedures as there may be more than one foci due to the diffuse and progressive nature of the disease. The success rates have been reported to be $32 \%, 45 \%$ and $66 \%$ after first, second and third attempts, respectively. ${ }^{21}$ Epicardial VT ablation has also been reported to be useful especially in patients with limited endocardial substrate and in those with refractory VT to improve long-term clinical outcomes. ${ }^{22}$

\section{INTRACARDIAC DEFIBRILLATORS}

The recommendations for ICD implantation for the prevention of SCD in patients with ARVD/ARVC include documented sustained VT or VF for those who are receiving optimal medical therapy and have a reasonable expectation of survival (Class I recommendation). For primary prevention of ICD implantation can be considered (Class IIa recommendation) in patients with extensive disease, including those with LV involvement, with one affected family member with SCD, or undiagnosed syncope when VT or VF has not been excluded as the cause of syncope, and who are receiving optimal medical therapy and have a reasonable expectation of survival. ${ }^{23}$

A recent study carried out to identify the predictors, characteristics and treatment of ventricular arrhythmias in patients with ARVC found that the incidence of VT was predicted by the presence of sustained ventricular arrhythmias

Table 1 Proposed recommendations for clinical management and prevention of SCD in patients with ARVD ${ }^{28}$

\begin{tabular}{|c|c|c|c|c|}
\hline Subgroups & Risk markers & Recommendations & Follow-up & ICD indication \\
\hline $\begin{array}{l}\text { Definite ARVD } \\
\text { High risk }\end{array}$ & $\begin{array}{l}\text { Aborted SCD } \\
\text { Sustained VT } \\
\text { Unexplained syncope }\end{array}$ & $\begin{array}{l}\text { Reduce physical } \\
\text { exercise } \\
\text { Avoid competitive } \\
\text { sport } \\
\beta \text {-blockers }\end{array}$ & $\begin{array}{l}\text { Annually including: } \\
\text { ECG } \\
\text { Cardiac imaging } \\
\text { (echocardiography vs CMR) } \\
\text { Holter } \\
\text { Exercise stress testing }\end{array}$ & Recommended \\
\hline $\begin{array}{l}\text { Definite ARVD } \\
\text { Moderate risk }\end{array}$ & $\begin{array}{l}\text { Extensive disease (severe RV dysfunction, large LV } \\
\text { involvement) } \\
\text { Non-sustained VT }\end{array}$ & $\begin{array}{l}\text { Reduce physical } \\
\text { exercise } \\
\text { Avoid competitive } \\
\text { sport } \\
\beta \text {-blockers }\end{array}$ & $\begin{array}{l}\text { Annually including: } \\
\text { ECG } \\
\text { Cardiac imaging } \\
\text { (echocardiography vs CMR) } \\
\text { Holter } \\
\text { Exercise stress testing }\end{array}$ & Consider \\
\hline $\begin{array}{l}\text { Definite ARVD } \\
\text { Low risk }\end{array}$ & Remaining patients with definite diagnosis of ARVD & $\begin{array}{l}\text { Reduce physical } \\
\text { exercise } \\
\text { Avoid competitive } \\
\text { sport } \\
\beta \text {-blockers }\end{array}$ & $\begin{array}{l}\text { Annually including: } \\
\text { ECG } \\
\text { Cardiac imaging } \\
\text { (echocardiography vs CMR) } \\
\text { Holter } \\
\text { Exercise stress testing }\end{array}$ & $\begin{array}{l}\text { Not } \\
\text { recommended }\end{array}$ \\
\hline $\begin{array}{l}\text { Asymptomatic mutation } \\
\text { carriers }\end{array}$ & Asymptomatic mutation-carrying relatives of ARVD & $\begin{array}{l}\text { Reduce physical } \\
\text { exercise } \\
\text { Avoid competitive } \\
\text { sport }\end{array}$ & $\begin{array}{l}\text { Annually including: } \\
\text { ECG } \\
\text { Cardiac imaging } \\
\text { (echocardiography vs CMR) } \\
\text { Holter } \\
\text { Exercise stress testing }\end{array}$ & $\begin{array}{l}\text { Not } \\
\text { recommended }\end{array}$ \\
\hline
\end{tabular}


prior to ICD implantations and T wave inversion in inferior leads and the only predictor for life-threatening arrhythmias was young age at enrolment. Antitachycardia pacing successfully terminated $92 \%$ of VT irrespective of VT cycle length. They have therefore recommended that all ICDs should be programmed for antitachycardia pacing, even for rapid VT. ${ }^{24}$ But it is important to remember that ICD implantation may not be entirely straightforward because of thin myocardium and difficulty in sensing because of fibrofatty deposits.

Once patients have developed RV or biventricular failure secondary to ARVC, therapy for heart failure management may be required.

In case of refractory disease, surgical therapies can be considered including (previously) total disconnection of RV free wall, RV exclusion surgery and heart transplantation. Total disconnection is associated with RV dilatation and failure, so RV exclusion surgery can be considered. ${ }^{25}$

As ARVC has been recognised an important cause of death in young athletes, mostly secondary to malignant ventricular arrhythmias caused by adrenergic stimulation, young patients with this condition are prohibited from vigorous athletic sports. This restriction applies even after ICD implantation, as most devices are programmed to deliver a maximum of six shocks only, which may not be enough to terminate malignant ventricular fibrillation ${ }^{26-28}$ (table 1).

\section{CONCLUSION}

ARVC is an inherited condition characterised by fibrofatty replacement of the RV. It is also a very important cause of sudden death in young individuals. The presentation can be non-specific, as was in our case making the diagnosis of this condition challenging. This in turn has implications on the patient's life and of his relatives and future generations. Therefore, it is imperative to make a thorough search for all possible causes so as not to miss the diagnosis of this rare condition and avoid delay in diagnosis and treatment.

\section{Competing interests None.}

Patient consent Obtained.

Provenance and peer review Not commissioned; internally peer reviewed.

\section{REFERENCES}

1 Frank R, Fontain G. Electrocardiologie de quatrecas de dysplasia ventriculair edroite arythmogene. Arch Mal Coeur Vaiss 1978;71:963-72.

2 Corrado D, Basso C, Thiene G. Arrhythmogenic right ventricular cardiomyopathy: diagnosis, prognosis and treatment. Heart 2003;83:588-95.

3 Shen WK, Edwards WD, Hammill SC, et al. Sudden unexpected non-traumatic death in 54 young athletes: a 30 year population based study. Am J Cardiol 1995;76:148-52.

4 Kies P, Bootsma M, Bax J, et al. Arrhythmogenic right ventricular dysplasia/ cardiomyopathy: screening, diagnosis, and treatment. Heart Rhythm 2006;3:225-34.

5 D'Amati G, Di Giola C, Giordano C, et al. Myocyte transdifferentiation: a possible pathogenic mechanism for arrhythmogenic right ventricular dysplasia. Arch Pathol Lab Med 2000;124:287-90.
6 Gemayel C, Pelliccia A, Thompson PD. Arrhythmogenic right ventricular cardiomyopathy. J Am Coll Cardiol 2001;38:1773-81.

7 Norman MW, McKenna WJ. Arrhythmogenic right ventricular dysplasia /cardiomyopathy: perspectives on disease. Z Kardiol 1999;88:550-4.

8 McKenna WJ, Thiene G, Nava A, et al. Diagnosis of arrhythmogenic right ventricular dysplasia/ cardiomyopathy. Task force of the Working Group Myocardial and Pericardial Diseases of the European Society of Cardiology and the scientific Council on Cardiomyopathies of the International Society and Federation of Cardiology. Br Heart J 1994;71:215-18.

9 Hamid MS, Norman M, Quraishi A, et al. Prospective evaluation of relatives for familial arrhythmogenic right ventricular cardiomyopathy/dysplasia reveals a need to broad diagnostic criteria. J Am Coll Cardiol 2002;16:1445-50.

10 te Riele ASJM, James CA, Rastegar N, et al. Yield of serial evaluation in at-risk family members of patients with. J Am Coll Cardiol 2014;64:293-301.

11 Marcus Fl, McKenna WJ, Sherrill D, et al. Diagnosis of arrhythmogenic right ventricular cardiomyopathy/dysplasia: proposed: modification of the task force criteria. Circulation 2010;121:1533-41.

12 Fontaine $\mathrm{G}$, Fontaliram F, Herbert JL, et al. Arrhythmogenic right ventricular dysplasia. Ann Rev Med 1999;50:17-35.

13 Marcus Fl, Fontaine G. Arrhythmogenic right ventricular dysplasia/cardiomyopathy: a review. Pacing Clin Electrophysiol 1995;18:1298-314.

14 Fontaine G, Sohal PS, Pioto O, et al. Partial block superimposed on right bundle branch block: a new ECG marker of the right ventricular dysplasia (abs). J Am Coll Cardiol 1997;29:110A.

15 Midiri M, Finazzo M. MR imaging of arrhythmogenic right ventricular dysplasia. Int J Card Imaging 2004;17:297-304.

16 Corrado B, Basso C, Thiene G. Arrhythmogenic right ventricular cardiomyopathy: diagnosis, prognosis and treatment. Heart 2000;83:588-95.

17 Danieli GA, Rampazzo A. Genetics of right ventricular cardiomyopathy: an update. Curr Opin Cardiol 2002;17:218-21.

18 Corrado D, Thiene G. Arrhythmogenic right ventricular cardiomyopathy/dysplasia: clinical impact of molecular genetic studies circulation. 2006;113:1634-7.

19 Wichter T, Broggrefe M, Haverkamp W, et al. Efficacy of antiarrhythmic drugs in arrhythmogenic right ventricular disease. Results in patients with inducible and non-inducible ventricular tachycardias. Circulation 1992;86:29-37.

20 Marcus GM, Glidden DV, Polonsky B, et al. Efficacy of anti-arrhythmic drugs in right ventricular arrhythmogenic dysplasia: a report from North American ARVC registry. J Am Coll Cardiol 2009;54:609-15.

21 Fontaine G, Tonet J, Gallais Y, et al. Ventricular tachycardia catheter ablation in arrhythmogenic right ventricular dysplasia: a 16 year experience. Curr Cardiol Rep 2000;2:498-506.

22 Garcia FC, Bazan V, Zado ES, et al. Epicardial substrate and outcome with epicardial ablation of ventricular tachycardia in arrhythmogenic right ventricular cardiomyopathy/dysplasia. Circulation 2009;120:366-75.

23 Pelliccia A, Corrado D, Bjornstad HH, et al. Recommendations for participation in competitive sport and leisure-time physical activity in individuals with cardiomyopathies, myocarditis and pericarditis. Eur J Cardiovasc Prev Rehabil 2006;13:876-85

24 Link MS, Laidlaw D, Polonsky B, et al. Ventricular arrhythmias in the North American multidisciplinary study of ARVC: predictors, characteristics, and treatment. J Am Coll Cardiol 2014;64:119-25.

25 Motta P, Mossad E, Savage R. Right ventricular exclusion surgery for arrhythmogenic right ventricular dysplasia with cardiomyopathy. Anesth Analg 2003:96:1598-602.

26 Furlanello G, Bertoldi A, Dallago M, et al. Cardiac arrest and sudden cardiac death in competitive athletes with arrhythmogenic right ventricular dysplasia. Pacing Clin Electrophysiol 1998;21:331-5.

27 Maron BJ, Isner JM, McKenna WJ. Twenty six Bethesda conference: recommendations for determining eligibility for competition in athletes with cardiovascular abnormalities. Task force 3: hypertrophic cardiomyopathy, myocarditis and other myopericardial diseases and mitral valve prolapse. J Am Coll Cardiol 1994;24:880-5.

28 Fernández-Armenta J, Brugada J. Arrhythmogenic right ventricular dyplasia. E-Journal of Cardiology Practice 2012;10:26. 